\title{
Perhitungan Ketebalan Bahan Komposit Karet Alam dan Timbal OksidaSebagai Pelindung Radiasi Sinar-X 100 Kev
}

\author{
Gunarwan Prayitno*, Pancatatva H. Gunawan \\ Program Studi Teknik Elektro, Fakultas Teknik, \\ Universitas Muhammadiyah Prof. DR. HAMKA, Jakarta. \\ Jl. Tanah Merdeka no.6 Pasar Rebo Jakarta Timur \\ Telp. +62-21-87782739, Fax. +62-21-87782739, Mobile. +62-815-3543-3089
}

\begin{abstract}
Abstrak - Telah dilakukan perhitungan ketebalan bahan komposit karet alam timbal oksida sebagai pelindung radiasi sinar-x $100 \mathrm{Kev}$. Perhitungan bertujuan untuk memperoleh ketebalan bahan proteksi radiasi yang aman bagi lingkungan atau pekerja dilingkungan medan radiasi. Perhitungan kemampuan daya serap bahan komposit karet alam timbal oksida dilakukan pada energy $100 \mathrm{Kev}$. Dasar perhitungan daya serap komposit karet alam timbal oksida sebasar 50 pphr (part per hundred rubber) sampai dengan 1000 pphr. Tebal komposit karet alam timbal oksida yang akan diukur setebal 2,5 mm. hasil perhitungan menunjukan bahwa ketebalan bahan komposit karet alam timbal oksida yang aman bagi pengguna atau para pekerja dimedan radiasi, apabila karet alam dicampur dengan timbal oksida sebanyak $550 \mathrm{pphr}$, nilai daya serap pada $550 \mathrm{pphr}$ telah memenuhi standart yang diizinkan.
\end{abstract}

\section{Pendahuluan}

Rekayasa pembuatan bahan perisai radiasi harus mempunyai dua sifat karakteristik, diantaranya, pertama mampu menyerap radiasi sinar $\mathrm{x}$ dan radiasi lainnya yang memepunyai karakteristik sama dengan sinar $\mathrm{x}$, kedua mempunyai daya serap yang tinggi. Karena bahan perisai yang akan dibuat diperuntukan atau dipergunakan oleh para pekerja yang berada di medan radiasi, maka persyaratan lain yang harus dipenuhi adalah tidak terlalu tebal dan elastis, artinya bila dipakai atau dipergunakan tidak terlalu berat dan tidak kaku. Yang dimaksud dengan daya serap yang tinggi terhadap sinar-x adalah untuk keamanan para pengguna. Koefisien daya serap bahan perisaiyang dibuat dibandingkan dengan daya serap timbal dengan ketebalan tertentu. Melalui perhitungan akan didapatkan ketebalan bahan perisai dan daya serap radiasi sesuai dengan standart nasional, sehingga pengguna terhindar dari paparan radiasi yang tidak diinginkan atau masih dalam batas yang diizinkan

\section{Dasar Teori}

Perhitungan ketebalan bahan perisai radiasi hanya untuk energy sinar-x $100 \mathrm{kev}$. Sedangkan perhitungan daya serap komposit karet alam berdasakan pada komposisi timbal oksida. Bahan komposisi timbal oksida yang akan dicampur dari nilai $550 \mathrm{pphr}$ (part per hundred rubber) sampai dengan 1000 pphr. Dalam hal ini karet alam sebagai material komposit, sedangkan timbal oksida sebagai bahan pengisi (filler) komposit. Diharapkan bahan campuran karet alam dan timbal oksida pada tingkat homogenitas yang tinggi , disamping itu distribusi timbal oksida dalam karet alam dapat terdistribusi sampai dengan pori-pori molekul karet alam. Telah dilakukan berbagai perhitungan ketebalan bahan perisai dengan kombinasi dua parameter, yaitu ketebalan karet alam dan timbal oksida sebagai pengisi. Hasil akhir yang diinginkan setipis mungkin karet alam dan sedikit mungkin timbal oksida, tetapi mempunyai daya serap yang tinggi. Nilai daya serap bahan komposit diequivalenkan terhadap daya serap pelat timbal dengan tebal tebal tertentu, dengan energy radiasi yang sama. Untuk menentukan daya serap bahan komposit terlebih dahulu menghitung koefisien serapan linier $\mu$ komposit berdasarkan energy sinar-x $100 \mathrm{kev}$. Nilai koefisien serapan linier komposit dihitung dari jenis unsur pembentuk komposit, antar lain timbal $(\mathrm{Pb})$, carbon $(\mathrm{C})$, dan Hydrogen (H). karet alam mempunyai rumus kimia $\mathrm{C}_{10} \mathrm{H}_{16}$, dan timbal oksida mempunyai rumus kimia $\mathrm{Pb}_{3} \mathrm{O}_{4}$.

Perhitungan untuk menentukan daya serap komposit, terlebih dahulu menghitung koefisien serapan linier $(\mu)$ pada energy $100 \mathrm{kev}$.

\section{Metode Perhitungan}

Dalam makalah ini akan dilakukan perhitungan daya serap bahan perisai radiasi setebal $2,5 \mathrm{~mm}$ karet alam dengan timbal oksida. Untuk menghitung koefisien serapan linier diperlukan parameter koefisien serapan masa untuk setiap unsur pembentuk senyawa karet alam dan timbal oksida 
pada energy $100 \mathrm{kev}$, parameter tersebut terlihat dalam table 1.

\begin{tabular}{|c|c|} 
Tabel 1. koefisien serapan masa pada $100 \mathrm{kev}$. \\
\hline Nama unsur & $\begin{array}{c}\text { Koefisien serapan masa } \\
(\mu / \rho) \mathrm{cm}^{2} / \mathrm{gr}\end{array}$ \\
\hline $\mathrm{H}$ & 0,294 \\
\hline $\mathrm{O}$ & 0,152 \\
\hline $\mathrm{C}$ & 0,149 \\
\hline $\mathrm{Pb}$ & 5,62 \\
\hline
\end{tabular}

Dengan menggunakan data koefisien serapan masa untuk setiap unsur pembentuk senyawa, maka dapat dihitung koefisien serapan masa senyawa karet alam dengan menggunakan persamaan 1 .

$$
(\mu / \rho) \text { senyawa }=\sum W \cdot(\mu / \rho)
$$

Dimana : $\mathrm{W}=$ fraksi berat unsur senyawa

Jadi bila koefisien serapan masa senyawa karet alam $\left(\mathrm{C}_{10} \mathrm{H}_{16}\right)$, akan dihitung dengan persamaan 1 , dengan mensubtitusi semua parameter, berat unsur, koefisien serapan unsur pada $100 \mathrm{kev}$, didapat hasil perhitungan sebagai berikut :

$$
\begin{aligned}
& \mu / \rho=\frac{10 \times 12}{120+16} \times 0,149+\frac{16 \times 1}{120 \times 16} \times 0,294 \\
& =0,1661 \mathrm{~cm} / \mathrm{gr} .
\end{aligned}
$$

Dengan cara yang sama didapat koefisien serapan masa senyawa timbal oksida $\left(\mathrm{Pb}_{3} \mathrm{O}_{4}\right)$ sebagai berikut :

$$
\begin{aligned}
& \mu / \rho=\frac{3 \times 207}{621+64} \times 5,62+\frac{4 \times 16}{621 \times 64} \times 0,152 \\
& =5,1091 \mathrm{~cm} / \mathrm{gr}
\end{aligned}
$$

Kedua hasil perhitungan diatas dipakai untuk menghitung koefisien serapan komposit dengan campuran atau komposisi dari 50 pphr sampai 1000 pphr. Artinya dengan komposisi 50 pphr berarti berat karet 100 gram dan berat timbal oksida 50 gram. Sebagai contoh koefisien serapan komposit dengan komposisi 50 pphr.

$$
\begin{aligned}
& \mu / \rho=\frac{100}{150} \times 0,1661+\frac{50}{150} \times 5,1091 \\
& =1,8137 \mathrm{~cm}^{2} / \mathrm{gr}
\end{aligned}
$$

Dengan cara yang sama untuk setiap kenaikan komposit pphr, maka dapat ditabelkan seperti terlihat pada table 2 .
Tabel 2. koefisien serapan komposit.

\begin{tabular}{|c|c|}
\hline $\begin{array}{c}\text { Komposisi } \\
\text { pphr }\end{array}$ & $\begin{array}{c}\text { Koefisien serapan komposit } \\
(\mu / \rho) \mathrm{cm}^{2} / g r\end{array}$ \\
\hline 50 & 1,8137 \\
\hline 100 & 2,6376 \\
\hline 150 & 3,1318 \\
\hline 200 & 3,4613 \\
\hline 250 & 3,6968 \\
\hline 300 & 3,8733 \\
\hline 350 & 4,0106 \\
\hline 400 & 4,1205 \\
\hline 450 & 4,2103 \\
\hline 500 & 4,2852 \\
\hline 550 & 4,3486 \\
\hline 600 & 4,4029 \\
\hline 650 & 4,4500 \\
\hline 700 & 4,4912 \\
\hline 750 & 4,5275 \\
\hline 800 & 4,5598 \\
\hline 850 & 4,5887 \\
\hline 900 & 4,6148 \\
\hline 950 & 4,6383 \\
\hline 1000 & 4,6597 \\
\hline & \\
\hline
\end{tabular}

Dengan mengetahui masa jenis karet alam $0,95 \mathrm{gr} / \mathrm{cm}^{2}$ dan masa jenis timbal oksida $9,3 \mathrm{gr} / \mathrm{cm}^{2}$, maka dapat dihitung volume masing - masing unsur dalam satu komposit setiap kenaikan nilai pphr, (dihitung menurut persamaan; $\mathrm{m}=\rho . \mathrm{v}$ atau $\mathrm{v}=\mathrm{m} / \rho$ ) didapat volume karet alam $=100 / 0,95 \mathrm{~cm}^{3}=$ $105,2631 \mathrm{~cm}^{3}$ dan volume timbal

oksida $=50 / 9,3=5,3763 \mathrm{~cm}^{3}$. Untuk komposisi yang berlainan didapat volume timbal oksida yang berbeda, dapat ditabelkan sebagai berikut, lihat table 2 .

Tabel 2. volume timbal oksida untuk komposisi pphr yang berlainan.

\begin{tabular}{|c|c|}
\hline $\begin{array}{c}\text { Komposisi } \\
\text { pphr }\end{array}$ & $\begin{array}{c}\text { Volume timbal oksida } \\
\left(\mathrm{Pb}_{3} \mathrm{O}_{4}\right)\end{array}$ \\
\hline 50 & 5,3763 \\
\hline 100 & 10,7526 \\
\hline 150 & 16,1290 \\
\hline 200 & 21,5053 \\
\hline 250 & 26,8817 \\
\hline 300 & 32,2580 \\
\hline 350 & 37,6344 \\
\hline 400 & 43,0107 \\
\hline 450 & 48,3870 \\
\hline 500 & 53,7644 \\
\hline 550 & 59,1397 \\
\hline 600 & 64,5161 \\
\hline 650 & 69,8924 \\
\hline 700 & 75,2688 \\
\hline 750 & 80,6451 \\
\hline 800 & 86,0215 \\
\hline 850 & 91,3978 \\
\hline 900 & 96,7741 \\
\hline
\end{tabular}




\begin{tabular}{|c|c|}
\hline 950 & 102,1505 \\
\hline 1000 & 107,5268 \\
\hline
\end{tabular}

Bahan perisai radiasi yang akan dihitung daya serapnya berukuran panjang $14,87 \mathrm{~cm}$ dan lebar $14,48 \mathrm{~cm}$ dan tebal 2,5 $\mathrm{mm}$, maka dapat dicari volume bahan perisai radiasi sebesar 54,5729 $\mathrm{cm}^{3}$. Dengan demikian volume karet dalam bahan komposit dihitung menurut persamaan 2 .

$$
V_{\text {karet }}=\frac{V_{\text {karet }}}{V_{\text {karet }}+V_{\text {timbal oksida }}} x V_{\text {bahan perisai }}
$$

Dengan menggunakan persamaan 2 dapat dihitung volume karet alam untuk setiap kenaika pphr, ditabelkan dalam table 3 .

Tabel 3. volume karet alam dalam bahan komposit

\begin{tabular}{|c|c|}
\hline $\begin{array}{c}\text { Komposisi } \\
\text { pphr }\end{array}$ & $\begin{array}{c}\text { volume karet alam dalam bahan komposit } \\
\left(\mathrm{cm}^{3}\right)\end{array}$ \\
\hline 50 & 51,9203 \\
\hline 100 & 49,519 \\
\hline 150 & 47,3219 \\
\hline 200 & 45,3150 \\
\hline 250 & 43,4713 \\
\hline 300 & 41,7718 \\
\hline 350 & 40,2992 \\
\hline 400 & 38,7452 \\
\hline 450 & 37,3869 \\
\hline 500 & 36,1227 \\
\hline 550 & 34,9416 \\
\hline 600 & 33,8351 \\
\hline 650 & 32,7966 \\
\hline 700 & 31,8199 \\
\hline 750 & 30,8997 \\
\hline 800 & 30,0312 \\
\hline 850 & 29,2102 \\
\hline 900 & 28,4329 \\
\hline 950 & 27,6959 \\
\hline 1000 & 26,9961 \\
\hline
\end{tabular}

Setelah mengetahui volume karet alam dalam bahan komposit, maka dapat diketahui volume timbal oksida dalam bahan komposit, dengan cara mengurangi volume bahan perisai dikurang volume karet alam, menggunakan persamaan 3 .

$$
V_{P_{3} o_{4}}=V_{\text {volume bahan perisai- }} V_{\text {karet }}
$$

Table 4 menunjukan volume timbal oksida dalam bahan komposit, dengan kenaikan komposisi pphr yang berbeda.

Tabel 4. volume timbal oksida dalam bahan komposit

\begin{tabular}{|c|c|}
\hline $\begin{array}{c}\text { Komposisi } \\
\text { pphr }\end{array}$ & $\begin{array}{c}\text { Volume timbal oksida } \\
\left(\mathrm{Pb}_{3} \mathrm{O}_{4}\right) \text { dalam bahan komposit }\left(\mathrm{cm}^{3}\right)\end{array}$ \\
\hline 50 & 2,6519 \\
\hline 707 & 4,6580 \\
\hline 150 & 7,2510 \\
\hline 200 & 9,2579 \\
\hline
\end{tabular}

Setelah mengetahui volume karet alam yang dicampur dengan timbal oksida dengan kenaikan nilai pphr yang berbeda, dilanjutkan dengan perhitungan berat karet alam yang dicampur timbal oksida dengan pphr yang berbeda. Perhitungan berat karet alam tersebut berdasarkan persamaan 4 .

$$
\boldsymbol{G}_{\text {karet alam }}=\boldsymbol{V}_{\text {karet alam }} \times \boldsymbol{\rho}_{\text {karet alam } \ldots}
$$

Dengan mensubtitusikan kerapatan karet alam sebesar 0,95 gr/cm3 dan volume karet alam (table 4) ke persamaan 4, akan didapat seperti dalam table 5 .

Tabel 5. Berat karet alam dalam bahan komposit.

\begin{tabular}{|c|c|}
\hline $\begin{array}{c}\text { Komposisi } \\
\text { pphr }\end{array}$ & $\begin{array}{c}\text { Berat karet alam dalam bahan komposit } \\
(\mathrm{gr})\end{array}$ \\
\hline 50 & 49,3249 \\
\hline 707 & 47,0391 \\
\hline 150 & 44,9558 \\
\hline 200 & 43,0492 \\
\hline 250 & 41,2977 \\
\hline 300 & 39,6832 \\
\hline 350 & 38,1902 \\
\hline 400 & 36,8070 \\
\hline 450 & 35,5175 \\
\hline 500 & 34,3165 \\
\hline 550 & 33,9450 \\
\hline 600 & 32,1433 \\
\hline 650 & 31,1567 \\
\hline 700 & 30,2289 \\
\hline 750 & 29,3547 \\
\hline 800 & 28,5296 \\
\hline 850 & 27,7496 \\
\hline 900 & 27,0112 \\
\hline 950 & 26,3111 \\
\hline 1000 & 25,6463 \\
\hline
\end{tabular}

Langkah berikut menghitung berat timbal oksida dengan masa jenis 9,3 gr/cm3, mengikuti persamaan 5 . 


$$
G_{P b_{3} o_{4}}=V_{P b_{3} o_{4}} x \rho_{P b_{3} o_{4}}
$$

Dimana $\mathrm{G}$ adalah berat timbal oksida dan $\mathrm{V}$ adalah volume, dan $\rho$ masa jenis timbal oksida dengan komposisi pphr yang berlainan, kemudian subtitusikan dalam persamaan 5, akan didapatkan hasil seperti dalam table 6 .

Tabel 6. Berat timbal oksida dalam bahan komposit.

\begin{tabular}{|c|c|}
\hline $\begin{array}{c}\text { Komposisi } \\
\text { pphr }\end{array}$ & $\begin{array}{c}\text { Berat timbal oksida dalam bahan komposit } \\
\text { (gr) }\end{array}$ \\
\hline 50 & 24,6626 \\
\hline 707 & 43,3139 \\
\hline 150 & 67,4343 \\
\hline 200 & 86,0984 \\
\hline 250 & 103,2448 \\
\hline 300 & 119,0502 \\
\hline 350 & 133,6661 \\
\hline 400 & 147,1976 \\
\hline 450 & 159,8298 \\
\hline 500 & 171,5868 \\
\hline 550 & 182,5710 \\
\hline 600 & 192,8615 \\
\hline 650 & 202,5195 \\
\hline 700 & 211,6029 \\
\hline 750 & 220,1607 \\
\hline 800 & 228,2378 \\
\hline 850 & 235,8731 \\
\hline 900 & 243,1020 \\
\hline 950 & 249,9561 \\
\hline 1000 & 256,4633 \\
\hline
\end{tabular}

Dilanjutkan dengan perhitungan masa jenis komposit untuk setiap komposisi pphr berbeda, mengikuti persamaan 6 .

$$
\rho=\frac{\left(G_{\text {krtalam }}+G_{\text {timal oksida }}\right)}{V_{\text {krt alam }}+V_{\text {timbal oksida }}}
$$

Subtitusikan parameter yang ada dalam persamaan dari data table-tabel sebelumnya, kemudian perhitunya dapat ditabelkan seperti dalam table 7.

\begin{tabular}{|c|c|}
\hline $\begin{array}{c}\text { Komposisi } \\
\mathrm{pphr}\end{array}$ & $\begin{array}{c}\text { Tabel 7. Masa jenis komposit } \\
\left(\mathrm{gr}^{\mathrm{c}} \mathrm{cm}^{3}\right)\end{array}$ \\
\hline 50 & 1,3557 \\
\hline 707 & 1,6557 \\
\hline 150 & 2,0594 \\
\hline 200 & 2,3665 \\
\hline 250 & 2,6486 \\
\hline 300 & 2,9086 \\
\hline 350 & 3,1491 \\
\hline 400 & 3,3717 \\
\hline 450 & 3,5795 \\
\hline 500 & 3,7729 \\
\hline 550 & 3,9537 \\
\hline 600 & 4,1230 \\
\hline 650 & 4,2819 \\
\hline 700 & 4,4313 \\
\hline
\end{tabular}

Copyright $\odot 2018$ FT-UHAMKA. - All rights reserved

\begin{tabular}{|c|c|}
\hline 750 & 4,5721 \\
\hline 800 & 4,7050 \\
\hline 850 & 4,8306 \\
\hline 900 & 4,9495 \\
\hline 950 & 5,0623 \\
\hline 1000 & 5,1694 \\
\hline
\end{tabular}

Pencampuran kedua unsur karet alam dan timbal oksida tersebut sesuai dengan standart nasional, begitu pula pengujiannya.setelah kedua bahan dicampur (disebut bahan komposit) menjadi bahan apron. Setelah menjadi bahan apron perlu dihitung koefisien serapan linier komposit. Perhitungan serapan linier mengikuti persamaan 7 .

$$
\begin{gathered}
\boldsymbol{\mu}=\text { koefisien serapan masa komposit } \mathrm{x} \text { masa } \\
\text { jenis komposit } \\
\ldots \ldots \ldots \ldots \ldots(7)
\end{gathered}
$$

Untuk setiap kenaikan pphr akan mempunyau koefisien serapan linier yang berbeda . hasil perhitungan ditabelkan dalam table 8 .

Tabel 8. koefisien serapan linier bahan komposit.

\begin{tabular}{|c|c|}
\hline $\begin{array}{c}\text { Komposisi } \\
\text { pphr }\end{array}$ & $\begin{array}{c}\text { koefisien serapan linier bahan } \\
\text { komposit }(\mu)\end{array}$ \\
\hline 50 & 2,4588 \\
\hline 707 & 4,3670 \\
\hline 150 & 6,4496 \\
\hline 200 & 8,1911 \\
\hline 250 & 9,7913 \\
\hline 300 & 11,2658 \\
\hline 350 & 12,6297 \\
\hline 400 & 13,8930 \\
\hline 450 & 15,0707 \\
\hline 500 & 16,1676 \\
\hline 550 & 17,1930 \\
\hline 600 & 18,1531 \\
\hline 650 & 19,0544 \\
\hline 700 & 19,9018 \\
\hline 750 & 20,7001 \\
\hline 800 & 21,4538 \\
\hline 850 & 22,1661 \\
\hline 900 & 22,4809 \\
\hline 950 & 23,4804 \\
\hline 1000 & 24,0887 \\
\hline
\end{tabular}

Setelah data-data yang diperlukan untuk menghitung daya serap radiasi sinar-x kev. Dilanjutkan dengan perhitungan daya serap radiasi sinar- $\mathrm{x}$ dengan kenaikan harga komposisi pphr berlainan dari 50 sampai 1000, untuk itu diperlukan persamaan 8 .

$$
D_{\text {serap }}=\left(1-e^{-\rho x}\right) x 100 \% \ldots \ldots \ldots . .8
$$

Dimana $: \mu=$ koefisien serapan linier bahan komposit

$\mathrm{x}=$ tebal karet alam $(2,5 \mathrm{~mm})$

Seminar Nasional TEKNOKA ke - 3, Vol. 3, 
Hasil perhitungan daya serap bahan komposit, ditabelkan pada table 9 .

\begin{tabular}{|c|c|}
\hline $\begin{array}{c}\text { Komposisi } \\
\text { pphr }\end{array}$ & $\begin{array}{c}\text { Tabel 9. Daya serap bahan komposit } \\
\text { (Ds) } \%\end{array}$ \\
\hline 50 & 45,92 \\
\hline 707 & 66,44 \\
\hline 150 & 80,06 \\
\hline 200 & 87,10 \\
\hline 250 & 91,35 \\
\hline 300 & 94,02 \\
\hline 350 & 95,57 \\
\hline 400 & 96,90 \\
\hline 450 & 97,68 \\
\hline 500 & 98,24 \\
\hline 550 & 98,89 \\
\hline 600 & 98,93 \\
\hline 650 & 99,15 \\
\hline 700 & 99,31 \\
\hline 750 & 99,43 \\
\hline
\end{tabular}

\section{Temuan dan Pembahasan}

Hasil perhitungan yang ditabelkan diatas hanya untuk serapan energy sinar-x $100 \mathrm{kev}$. Perhitungan daya serap berdasarkan nilai pphr part per hundred rubber).dimisalkan nilai pphr 50, artinya berat karet alam 100 gram dan berat timal oksida 50 gram. Setiap kenaikan pphr akan mempengaruhi daya serap. Untuk mendapatkan koefisien serap linier bahan komposit (persamaan 8) $\mu$, parameterparameter penunjang untuk menuju nilai tersebut harus dihitung terlebih dahulu. Table 1 sampai table 7 diatas merupaka hasil perhitungan parameter penunjang. Hasil perhitungan daya serap bahan komposit karet alam timbal oksida diverifikasi dengan daya serap plat timbal terhadap sinar-x, verifikasi yang dilakukan pada tebal plat $0,1 \mathrm{~mm}$ sampai dengan $0,75 \mathrm{~mm}$. Pada tebal berapa karet alam harus dicampur dengan timbal oksida, berdasarkan nilai pphr. Sehingga mempunyai nilai daya serap sinar-x sesuai standart nasional yang diizinkan. Nilai daya serap bahan komposisi yang diizinkan masih dalam rentang $0,1 \mathrm{~mm}$ sampai $0,75 \mathrm{~mm}$, plat timbal. Batasan yang harus dipenuhi dalam perhitungan karet alam dengan timbal oksida adalah :

1. Mempunyai daya serap yang tinggi terhadap sinar-x $100 \mathrm{kev}$

2. Ringan tidak menambah beban para pengguna

3. Elastis, fleksibel, dan lentur

4. Tahan terhadap gaya Tarik.

Dengan demikian hassil perhitungan (table 8) untuk memenuhi 4 kriteria diatas disimpulkan bahwa dengan tebal karet alam 2,5 mm dapat dicampur dengan nilai pphr 300. Pada harga ini equivalen dengan daya serap plat timbal setebal $0,3 \mathrm{~mm}$. hanya dengan mencampur $300 \mathrm{pphr}$ telah memenuhi standart nasional SNI. Dengan daya serap 94,02 $\%$ diatas nilai SNI para pengguna akan merasa aman.

\section{Kepustakaan}

[1] Standart Nasional Indonesia (SNI) 18- 6478 - 2000; Apron Proteksi Radiasi Sinar-x, Badan Standarisasi Nasional, Jakarta 2000.

[2] Standart Nasional Indonesia (SNI) 06-6041-1999, Lembaga Vulkanisasi Karet Timbal untuk Perisai Sinar-x, Badan Standarisasi Nasional Indonesia, Jakarta 1999.

[3] Standart Nasional Indonesia (SNI), 18-6479- 2000 ; Pakaian Proteksi sinar-x untuk pasien, Badan Standarisasi Nasional, Jakarta 2000 .

[4] Standart Nasional Indonesia (SNI), 18-6480- 2000, Metode Pengujian Ekivalen Timbal untuk Peralatan sinar-x, Badan Standarisasi Nasional , Jakarta 2000. 